\title{
Bearing capacity of thin-walled shallow foundations: an experimental and artificial intelligence-based study*
}

\author{
Hossein REZAEI ${ }^{1}$, Ramli NAZIR ${ }^{2}$, Ehsan MOMENI ${ }^{\dagger+1,2}$ \\ ( ${ }^{1}$ Faculty of Engineering, Lorestan University, Khorram Abad 68151-44316, Iran) \\ ( ${ }^{2}$ Department of Geotechnics and Transportation, Faculty of Civil Engineering, Universiti Teknologi Malaysia, Johor 81310, Malaysia) \\ †E-mail: mehsan23@live.utm.my \\ Received Feb. 10, 2015; Revision accepted July 10, 2015; Crosschecked Mar. 16, 2016
}

\begin{abstract}
Thin-walled spread foundations are used in coastal projects where the soil strength is relatively low. Developing a predictive model of bearing capacity for this kind of foundation is of interest due to the fact that the famous bearing capacity equations are proposed for conventional footings. Many studies underlined the applicability of artificial neural networks (ANNs) in predicting the bearing capacity of foundations. However, the majority of these models are built using conventional ANNs, which suffer from slow rate of learning as well as getting trapped in local minima. Moreover, they are mainly developed for conventional footings. The prime objective of this study is to propose an improved ANN-based predictive model of bearing capacity for thin-walled shallow foundations. In this regard, a relatively large dataset comprising 145 recorded cases of related footing load tests was compiled from the literature. The dataset includes bearing capacity $\left(Q_{\mathrm{u}}\right)$, friction angle, unit weight of sand, footing width, and thin-wall length to footing width ratio $\left(L_{\mathrm{w}} / B\right)$. Apart from $Q_{\mathrm{u}}$, other parameters were set as model inputs. To enhance the diversity of the data, four more related laboratory footing load tests were conducted on the Johor Bahru sand, and results were added to the dataset. Experimental findings suggest an almost 0.5 times increase in the bearing capacity in loose and dense sands when $L_{\mathrm{w}} / B$ is increased from 0.5 to 1.12 . Overall, findings show the feasibility of the ANN-based predictive model improved with particle swarm optimization (PSO). The correlation coefficient was 0.98 for testing data, suggesting that the model serves as a reliable tool in predicting the bearing capacity.
\end{abstract}

Key words: Thin-walled foundation, Sand, Bearing capacity, Artificial neural network (ANN), Particle swarm optimization (PSO)

http://dx.doi.org/10.1631/jzus.A1500033

CLC number: TU43

\section{Introduction}

Foundations are generally categorized into deep and shallow (spread) foundations. The use of the latter is recommended from the economic perspective if the subsurface condition is good enough (Gibbens and Briaud, 1995). Nevertheless, bearing capacity and allowable settlement of foundations are of

\footnotetext{
${ }^{\ddagger}$ Corresponding author

* Project supported by the Science Fund of Malaysian Ministry of Science, Technology and Innovation (No. \#4S077)

(DDCID: Hossein REZAEI, http://orcid.org/0000-0003-0766-5833; Ehsan MOMENI, http://orcid.org/0000-0003-4084-485X

(C) Zhejiang University and Springer-Verlag Berlin Heidelberg 2016
}

great concern to geotechnical engineers (Momeni et al., 2013). The former is often referred to a maximum load that the soil can tolerate before its failure. A number of researchers (Terzaghi, 1943; Meyerhof, 1963; Vesic, 1973) formulated bearing capacity theory, which for reasons of brevity is not repeated here as it is well established.

However, in the recent past, the use of skirted shallow foundations, or in other words thin-walled spread foundations, is highlighted in several studies. In this regard, Al-Aghbari and Mohamedzein (2004) as well as Eid et al. (2009) mentioned that providing skirts (thin-walls) for the spread foundation forms an enclosure in which the soil is confined. They hypothesized that the existence of such walls results 
in transferring the foundation loads to the laterally confined soil and then to the deeper sand layers that are more confined than shallow layers due to an increase in overburden pressure. Providing thinwalls for foundations can increase the total depth of failure and change the failure pattern of the soil which may lead to more shear strength mobilization.

Al-Aghbari and Mohamedzein (2004) reported the increase in bearing capacity by a factor in the range of 1.5 to 3.9 when skirt foundations are used instead of simple (surface) foundations. In another study, Al-Aghbari and Dutta (2008) addressed an increase in the bearing capacity from $11.2 \%$ to $70 \%$ due to incorporation of structural skirts.

Eid (2013) mentioned that incorporation of skirts leads to significantly higher bearing capacity. According to his conclusion, depending on thin-wall length to footing width ratio $\left(L_{\mathrm{w}} / B\right)$, thin-walled foundations exhibited 1.4 to 3 times higher bearing capacity in comparison with simple foundations.

Nazir et al. (2013) introduced a specific thinwalled spread foundation (Fig. 1) suitable for industrialized building systems. Their numerical investigations showed the workability of the aforementioned foundation. Momeni et al. (2015b) reported that the use of a thin-walled spread foundation compared with a surface foundation can increase the bearing capacity by almost twice in both loose and dense sands.
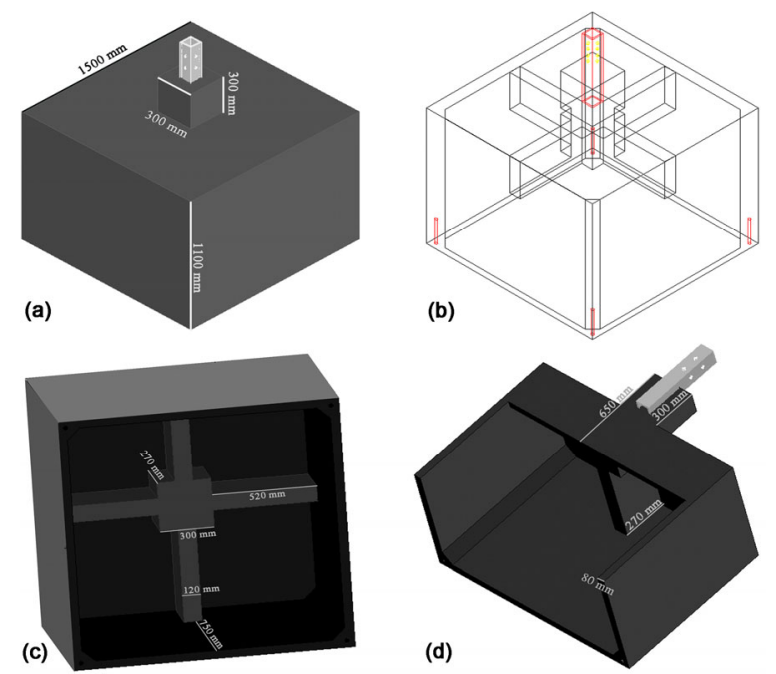

(c)

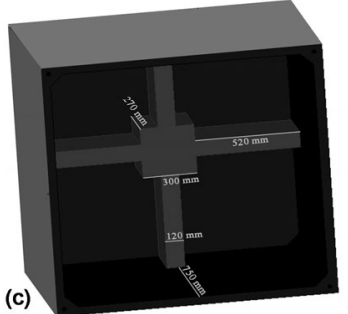

Fig. 1 Thin-walled spread foundation: (a) isometric view; (b) bracing system; (c) bottom view; (d) cross sectional view. Reprinted from (Momeni et al., 2015b), Copyright 2015, with permission from ICE Publishing
Nevertheless, the fact that famous bearing capacity equations are proposed for conventional spread foundations rather than thin-walled spread foundations encouraged the authors to develop a predictive model of bearing capacity for such footings. As highlighted in the next section, the use of an artificial neural network (ANN) in foundation engineering problems, i.e., bearing capacity, is recommended in many studies (Shahin, 2015).

However, the majority of the predictive models of bearing capacity are built using a conventional ANN which suffers from getting trapped in local minima and a slow rate of learning. In this regard, several studies reported the use of optimization algorithms, such as the genetic algorithm (GA) and particle swarm optimization (PSO) algorithm, for enhancing the ANN performance (Section 3.4).

In this study, an attempt was made to develop an improved ANN-based predictive model of bearing capacity for thin-walled spread foundations. For this reason, four small scale footing load tests were conducted in the laboratory. The laboratory tests results as well as a relatively large number of related recorded cases of footing load tests compiled from literature formed the required dataset for developing the predictive model proposed in this study.

It is worth mentioning that as far as authors are aware, there is no comprehensive and wellestablished ANN-based predictive model for this kind of foundation (thin-walled spread foundations). Thus, the study presented here is different from previously proposed predictive models of bearing capacity. In addition, the work presented here takes advantage of a relatively large dataset, i.e., 149 recorded cases, which significantly reduces the likelihood of model over fitting (Zorlu et al., 2008).

\section{Related predictive models}

Successful application of a conventional ANN in geotechnical engineering is addressed in many studies (Shahin et al., 2001; Jahed Armaghani et al., 2014; Tonnizam Mohamad et al., 2014). As tabulated in Table 1, in foundation engineering, numerous researchers showed the workability of ANNs for predicting either settlement or bearing capacity of foundations. Table 1 also gives the dataset number, the coefficient of determination values, as well as 
Table 1 Related works on the application of ANN in foundation engineering

\begin{tabular}{lcccc}
\hline \multicolumn{1}{c}{ Source } & Dataset number & Major inputs & Footing type & Reliability, $R^{2}$ \\
\hline Goh (1996) & 116 & PS, HW & Pile & 0.93 \\
Lok and Che (2004) & 105 & $G, \mathrm{SW}$ & Pile & 0.92 \\
Soleimanbeigi and Hataf (2006) & 351 & $G, \phi, \gamma$ & Spread & 0.94 \\
Padmini et al. (2008) & 97 & $\gamma, G, \phi$ & Spread & 0.98 \\
Ornek et al. (2012) & 28 & $G, S$ & Spread & 0.95 \\
Kiefa (1998) & 59 & $G, \phi, \sigma$ & Pile & 0.91 \\
Pal and Deswal (2008) & 105 & $G, \mathrm{SW}$ & Pile & 0.98 \\
Zhao et al. (2010) & 9 & $N, \phi, G, \gamma, C$ & Pile & - \\
Benali and Nechnech (2011) & 80 & $G, C, \sigma$ & Pile & 0.84 \\
Momeni et al. (2014) & 50 & $G, \mathrm{HW}, \mathrm{PS}, \mathrm{HD}$ & Pile & 0.99 \\
Momeni et al. (2015a) & 36 & $G, \mathrm{PS}, N$ & Pile & 0.94 \\
\hline
\end{tabular}

$N$ : standard penetration test $N$ value; $G$ : geometrical properties of footings (piles or shallow foundations); $q$ : footing net applied pressure; $\phi$ : soil friction angle; $\gamma$. unit weight of soil; $\sigma$ : effective stress of the soil; $S$ : settlement of the footing; SW: stress-wave data; $C$ : soil cohesion; HW: hammer weight; HD: drop height; PS: pile set

the major input parameters of the recently proposed predictive models. According to Table 1, footing geometrical and soil properties are influential parameters in ANN-based predictive models.

\section{Methods}

\subsection{Artificial neural network}

The application of ANN as a promising tool in solving geotechnical and rock engineering problems has drawn considerable attention (Meulenkamp and Alvarez Grima, 1999). In essence, the use of ANNs as function approximation tools is of interest when the contact nature between the influential parameters on model output(s) and the output parameter(s) is unknown. In other words, when the underlying problem is difficult to model explicitly or it is difficult to find a close form solution for a problem, the use of ANNs is advantageous (Garrett, 1994). Nevertheless, a typical ANN consists of a number of interconnected layers (input, hidden(s), and output(s) layers). Each layer comprises one or more processing units known as neurons or nodes. The nodes of different layers are connected to each other through adjustable connection weights. However, as reported by Hornik et al. (1989), usually one hidden layer is good enough for approximating any continuous function.

The use of more hidden layers can increase the model complexity and the likelihood of model over fitting, which should be avoided in designing ANNs.
Before interpreting new information, the network needs to be trained.

The back-propagation (BP) algorithm is the most commonly implemented training algorithm in ANNs (Dreyfus, 2005). In essence, the role of the $\mathrm{BP}$ algorithm is to optimize the connection weights which lead to a desirable mean square error (MSE). The MSE is referred as the square difference between the predicted outputs and the target outputs. The best outputs are often predicted after several feedforward-backward passes. In the forward pass, the data presented to input layer (denoted by $I i$ in Fig. $2, i=1,2, \ldots)$ start to feedforward. In this step, each input node transmits several signals to the hidden nodes. In other words, each node in the hidden layer ( $N i$ in Fig. 2) receives the sum of weighted input signals (input values multiplied by random connection weights, $\sum W_{i j}$ in Fig. 2) as well as a threshold value known as bias ( $B i$ in Fig. 2). The output of each hidden neuron is subsequently obtained by applying a transfer function (usually a sigmoid function) on the net input values of hidden neurons (Fig. 2). The same procedure is repeated for the next layers until the output ( $O$ in Fig. 2 ) is predicted. Having known the actual outputs, if the predicated outputs are not desirable, the network should back propagate and update the connection weights. This process is known as backward pass. These passes are repeated until the desirable outputs are predicted. Readers are referred to fundamental artificial intelligence books for more information about ANNs (Fausett, 1994). 


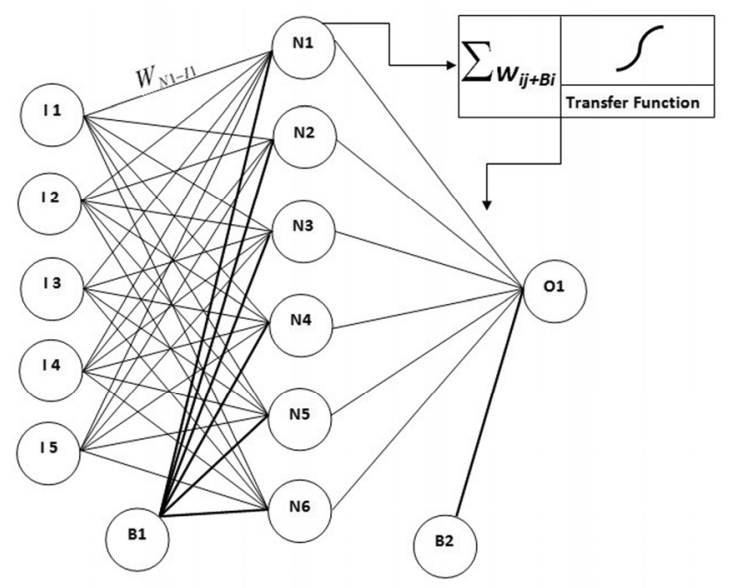

Fig. 2 Typical architecture of ANN. Reprinted from (Momeni et al., 2014), Copyright 2014, with permission from Elsevier

\subsection{Particle swarm optimization}

Particle swarm optimization (PSO) is an evolutionary computation algorithm which implements a nonlinear procedure for solving a continuous global optimization problem. PSO was proposed by Kennedy and Eberhart (1995). In PSO, particles are candidate solutions of a problem. At first, a random number of particles forms a population. Each particle is given a random position and velocity. Subsequently, an iterative procedure is implemented to find the best solution (often global minima). The particle positions, at this stage, are adjusted based on the particle experience as well as the swarm experience. To be more specific, each particle keeps track of its best position as well as the global best position of other particles. In PSO terminology, the best position which a particle has experienced and the global best experience achieved by other particles are referred as $\boldsymbol{p}_{\text {best }}$ and $\boldsymbol{g}_{\text {best }}$, respectively.

Nevertheless, PSO is trained to propel towards its $\boldsymbol{p}_{\text {best }}$ and $\boldsymbol{g}_{\text {best. }}$. For this reason, a new velocity term is determined for each particle based on its distance from its $\boldsymbol{p}_{\text {best }}$ and $\boldsymbol{g}_{\text {best }}$. In the next step, these two $\boldsymbol{p}_{\text {best }}$ and $\boldsymbol{g}_{\text {best }}$ velocities are randomly weighted to generate a new velocity value for a specific particle. As a consequence, in the next iteration, the position of the particle will be affected (Eberhart and Shi, 2001). The relatively simple PSO velocity update and movement equations are given in the following lines. They are mainly used for determining the actual movement of a particle and adjusting the velocity vector.

$$
\begin{aligned}
& \boldsymbol{V}_{\text {new }}=\boldsymbol{V}+r_{1} c_{1} \times\left(\boldsymbol{p}_{\text {best }}-\boldsymbol{p}\right)+r_{2} c_{2} \times\left(\boldsymbol{g}_{\text {best }}-\boldsymbol{p}\right), \\
& \boldsymbol{p}_{\text {new }}=\boldsymbol{p}+\boldsymbol{V}_{\text {new }},
\end{aligned}
$$

where $c_{1}$ and $c_{2}$ are pre-defined coefficients, $r_{1}$ and $r_{2}$ are random values in the range $(0,1)$ sampled from a uniform distribution, $\boldsymbol{V}_{\text {new }}$ and $\boldsymbol{V}$ are the new and current velocity vectors, $\boldsymbol{p}_{\text {new }}$ and $\boldsymbol{p}$ are the new and current positions of particles, respectively.

\subsection{Genetic algorithm}

The genetic algorithm (GA), which was first introduced by Holland (1975), is one of the most popular evolutionary algorithms. Similar to PSO, in GA there are some candidate solutions that mature over time to reach an optimal solution. In GA terminology, the candidate solutions, which form an initial population, are called chromosomes. Chromosomes are in the form of a linear string comprising 0 and 1 . Similar to other optimization algorithms, GA starts with defining the optimization parameters and cost function (usually MSE), and ends when the stopping criteria are met. Each iteration in GA is termed generation. However, to produce the next generation in GAs, three genetic operations should be performed. These operators include reproduction, crossover, and mutation.

As stated by Momeni et al. (2014), reproduction is a step in which the best chromosomes are selected according to their scaled values and based on the given criteria of fitness, subsequently they will be passed to the next generation. Crossover, on the other hand, generates offspring (also called new individuals) by combining certain parts of the parents. In essence, as mentioned by Jadav and Panchal (2012), in the crossover process, two parents as well as an arbitrary crossover point are selected. Subsequently, through merging the left side genes of the first parent with right side genes of the second parent, the first offspring is generated. For creating the second offspring, an inverse procedure is repeated. The last GA operator is mutation. This operator is utilized to describe a sudden change which might appear in the allele of a chromosome. The negligible arbitrary changes applied to the element of a chromosome help GA to search a broader space. A typical GA is described in the following lines: 
1. Forming a group of candidate solutions (initial population);

2. Finding the cost of each chromosome:

(1) Preferentially transferring the chromosomes with lower costs to the next generation;

(2) Applying crossover and mutation function for creating new chromosomes;

3. Checking convergency (if the stopping criterion is not met, repeat the second step);

4. Introducing the fittest chromosome as the solution.

\subsection{Hybrid artificial neural network}

It was mentioned above that the main reasons behind using the optimization algorithms are the ANN deficiencies in getting trapped in local minima as well as the ANN slow rate of learning (Lee et al., 1991). However, recent literature suggested several optimization algorithms (i.e., PSO, GA) for enhancing ANN performance like the study of Rashidian and Hassanlourad (2013) on a GA enhancing ANN performance and improving on its drawbacks. Such a conclusion was also highlighted in other recent studies (Majdi and Beiki, 2010; Jadav and Panchal, 2012; Liu et al., 2012). PSO beneficial effects were covered by Momeni et al. (2015c). PSO as a global search algorithm can be implemented to improve ANNs' performance by adjusting the weight and bias of ANNs (Shi and Eberhart, 1999; Mendes et al. 2002). In fact, PSO and GA as global search algorithms help ANN as a local search algorithm to avoid it getting trapped in local minima and to find global minima.

It was discussed earlier that finding the minimum MSE is the main aim in ANNs. In the improved ANNs, the ANN connection weights are trained with the optimization algorithms rather than with a conventional back-propagation learning algorithm. The reason is to increase the chance of finding global minima (the least MSE).

\section{Model dataset}

To obtain a sufficient size of dataset for developing the predictive model of bearing capacity, an extensive literature review gave a database compris- ing 145 recorded cases of thin-walled footing load tests (Villalobos, 2007; Al-Aghbari and Mohamedzein, 2004; Eid et al., 2009; Tripathy, 2013; Wakil, 2013; Momeni et al., 2015b). The results of four laboratory tests (to be discussed later) were also added to the dataset to enhance the diversity of the data. Table 2 summarizes the minimum, maximum, as well as the average values of the dataset used in this study. Needless to say, the bearing capacity of thinwalled spread foundations in cohesionless soils is related to footing width $B$, soil internal friction angle $\phi$, soil unit weight $\gamma$, and $L_{\mathrm{w}} / B$. Therefore, these parameters were used as the input parameters of the predictive models. The bearing capacity $\left(Q_{\mathrm{u}}\right)$ of the thin-walled spread foundations in cohesionless soils was set as the model output.

Table 2 Summarized dataset

\begin{tabular}{cccccc}
\hline Value & $\begin{array}{c}B \\
(\mathrm{~mm})\end{array}$ & $L_{\mathrm{w}} / B$ & $\phi\left(^{\circ}\right)$ & $\begin{array}{c}\gamma \\
\left(\mathrm{kN} / \mathrm{m}^{3}\right)\end{array}$ & $\begin{array}{c}Q_{\mathrm{u}} \\
(\mathrm{kPa})\end{array}$ \\
\hline Min & 36.55 & 0 & 29.23 & 10.34 & 17.1 \\
Max & 144 & 2 & 44.75 & 18.2 & 8005 \\
Average & 71.16 & 0.9 & 38 & 15.5 & 607 \\
\hline
\end{tabular}

\section{Model development procedure}

In the first step, a parametric study was utilized for determining the suitable PSO-based ANN parameters comprising swarm size, network architecture, and the number of iterations. For this purpose, a MATLAB code was prepared. Subsequently, based on an educated guess, an ANN model with one hidden layer and seven hidden neurons was set to be an initial model. Random sampling was used for dividing the dataset into two subsets: training and testing. The use of this procedure was suggested in several studies (Alvarez Grima and Babuška, 1999; Singh et al., 2001; Rabbani et al., 2012; Tonnizam Mohamad et al., 2014). Nevertheless, it should be mentioned that $80 \%$ of the data were used for network training and the other $20 \%$ were used for testing the prediction power of the model. The first step in the parametric study was to determine the number of iterations as well as the optimum swarm size. The former is often used as the termination criterion. The termination 
criterion is a condition that, upon being met, ends the iterative procedure. Therefore, an effort was made to investigate the effect of iteration numbers on the network performance.

A model with a default 800 iterations, 150 particle size, and acceleration constants $\left(c_{1}\right.$ and $\left.c_{2}\right)$ equal to 2 was built. Fig. 3 suggests there is no remarkable change in the MSE after 450 iterations. Hence, 450 iterations was set to be the maximum number of iterations.

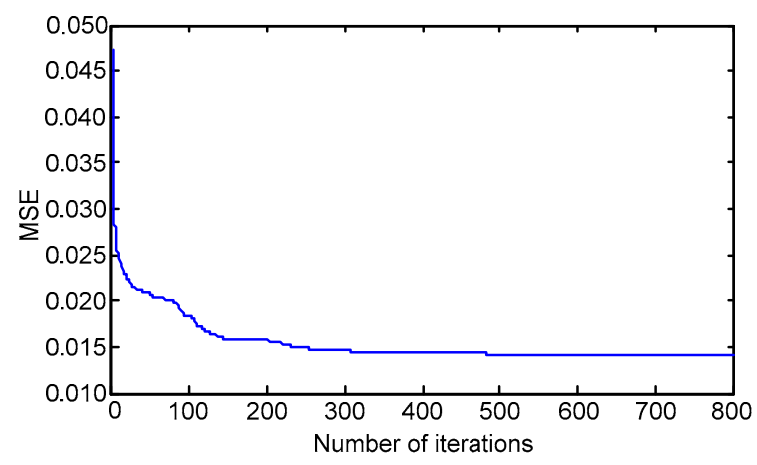

Fig. 3 Effect of iteration numbers on model performance

The best swarm size also needs to be determined. It is worth mentioning that enlarging the swarm size (number of particles) increases the model complexity as well as the training time, while small swarm size may negatively affect the performance of the model. Hence, a sensitivity analysis was performed to find the optimum number of particles. For this purpose, the effect of a wide range of swarm sizes (70-800 from small to large) on model performances was studied, and the MSE was determined in each analysis.

Other PSO parameters were not changed during this step. That is, to find the best PSO structure, the number of iterations was set to be 450 and acceleration constants $\left(c_{1}\right.$ and $\left.c_{2}\right)$ equal to 2 were used as suggested by Shi and Eberhart (1998) and Mendes et al. (2002). Fig. 4 shows the values of MSE obtained for different swarm sizes.

As displayed in Fig. 4, the model built with 600 particles performed best with an MSE of 0.009 . Therefore, the number of particles was set to be 600 . It should be mentioned that before modelling, the data were normalized to values between -1 and 1 .

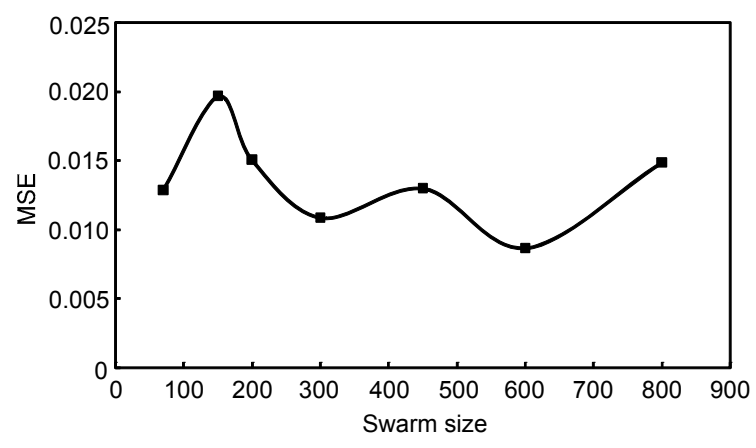

Fig. 4 Effect of swarm size on model performance

After determining the optimum PSO parameters, the network architecture was designed. To obtain the proper network design, four hybrid models were run with different numbers of hidden neurons in one layer. However, for evaluating the performance of the model, $R$ values of the testing dataset were studied.

Nevertheless, 4, 5, 6, or 7 neurons were trialed in each hidden layer to obtain the proper number of neurons. Table 3 shows the analyses results. The tabulated results in Table 3 indicate that the model which was built with seven neurons in the hidden layer (the fourth model) outperforms the other models. The correlation coefficient and MSE, equal to 0.98 and 0.005 , respectively, for the testing dataset suggest the model superiority. Therefore, the architecture of this model was considered to be optimum for the predictive model of bearing capacity.

Table 3 Prediction performance of different PSObased ANN models

\begin{tabular}{ccccccc}
\hline \multirow{2}{*}{ Model } & \multirow{2}{*}{$\begin{array}{c}\text { Number } \\
\text { of nodes }\end{array}$} & \multicolumn{2}{c}{ Training } & & \multicolumn{2}{c}{ Testing } \\
\cline { 3 - 4 } \cline { 6 - 7 } & & MSE & $R$ & & MSE & $R$ \\
\hline 1 & 4 & 0.016 & 0.88 & & 0.020 & 0.81 \\
2 & 5 & 0.008 & 0.92 & & 0.037 & 0.86 \\
3 & 6 & 0.013 & 0.88 & & 0.020 & 0.97 \\
4 & 7 & 0.015 & 0.91 & & 0.005 & 0.98 \\
\hline
\end{tabular}

In developing a GA-based ANN predictive model, a procedure similar to the PSO-based ANN was utilized to determine the GA parameters. However, in the interests of brevity, it is not repeated here. Nevertheless, after conducting the parametric study, it was found that the best GA-based ANN for the problem of interest is expected when the GA parameters presented in Table 4 are used. After finding the 
suitable GA parameters, similar to the ANN model improved with PSO, the optimum number of hidden neurons in the GA-based ANN model was obtained. This is tabulated in Table 5 where the performances of various models were evaluated using the MSE values and correlation coefficients. As displayed in Table 5, the models consisted of various hidden nodes, i.e., 4, 5, 6, and 7 in one hidden layer. According to Table 5, the last model, i.e., Model 4, works better. The correlation coefficient and MSE of 0.87 and 0.010 , respectively, for testing dataset indicate that the aforementioned model performs best. The results of this predictive model will be discussed in Section 7.

Table 4 Optimum GA parameters

\begin{tabular}{lc}
\hline \multicolumn{1}{c}{ Parameter } & Description \\
\hline Mutation probability & $1 \%$ \\
Recombination percentage & $9 \%$ \\
Single point crossover & $90 \%$ \\
Selection method & Tournament \\
Population size & 230 \\
Generation number & 45 \\
\hline
\end{tabular}

Table 5 Prediction performance of various GA-based ANN models

\begin{tabular}{ccccccc}
\hline \multirow{2}{*}{ Model } & \multirow{2}{*}{$\begin{array}{c}\text { Number } \\
\text { of nodes }\end{array}$} & \multicolumn{2}{c}{ Training } & & \multicolumn{2}{c}{ Testing } \\
\cline { 3 - 4 } \cline { 6 - 6 } & & MSE & $R$ & & MSE & $R$ \\
\hline 1 & 4 & 0.043 & 0.65 & & 0.023 & 0.70 \\
2 & 5 & 0.050 & 0.60 & & 0.018 & 0.82 \\
3 & 6 & 0.038 & 0.69 & & 0.025 & 0.76 \\
4 & 7 & 0.040 & 0.71 & 0.010 & 0.87 \\
\hline
\end{tabular}

To have a better understanding, the prediction performances of the hybrid models were compared with those of a conventional ANN. For this purpose, using an ANN model constructed with seven hidden neurons in one hidden layer, the bearing capacity of the thin-walled spread foundations were predicted. The Levenberg-Marquardt (LM) learning algorithm was used for training the network. More details on this learning algorithm (its efficiency for training) were discussed in the study conducted by Hagan et al. (1996). Nevertheless, like improved ANN models, in the conventional ANN model, random sampling was used $(80 \%$ of the data for training the model and the rest for testing purpose).

\section{Laboratory test procedure}

In this section the procedure implemented in conducting the footing load tests is highlighted. In this study, the load carrying capacity of a specific thin-walled foundation proposed by Nazir et al. (2013) (Fig. 1) is investigated. The footing is referred to as an industrialized building systems (IBS) footing mainly because it is developed to be used in IBS. In essence, two IBS footings as shown in Fig. 5 were loaded in the Johor Bahru sand (in loose and dense states). The sand particles ranged from $0.063 \mathrm{~mm}$ to $1.18 \mathrm{~mm}$. The mean grain size $\left(D_{50}\right)$, effective grain size $\left(D_{10}\right)$, and coefficient of uniformity $C_{\mathrm{u}}$ were $0.5 \mathrm{~mm}, 0.142 \mathrm{~mm}$, and 3.52 , respectively. The unit weight and internal friction angle for loose and dense sands were $14.26 \mathrm{kPa}$ and $29.23^{\circ}, 15.54 \mathrm{kPa}$ and $36.24^{\circ}$, respectively. Several studies addressed the minimization of scale effect if the ratio of footing width to soil mean grain size exceeds 100 (Habib, 1974; Taylor, 1995; Kalinli et al., 2011). Therefore, knowing the $D_{50}$ of the sand, small scale IBS footings of width $80 \mathrm{~mm}$ (18.75 times smaller compared with proposed full scale in Fig. 1) were prepared. Fig. 5 also shows the dimensions of the footings used in this study. As shown in Fig. 5, apart from $L_{\mathrm{w}} / B$, other dimensions are the same for both footings.
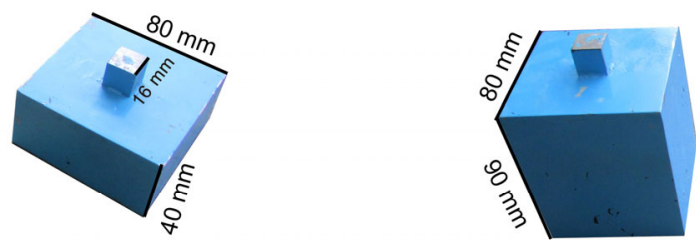

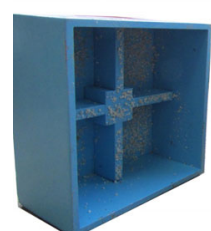

(a)

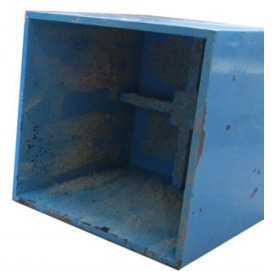

(b)
Fig. 5 Thin-walled shallow foundations used in this study (a) IBS footing with shorter wall; (b) IBS footing with longer wall

The footings were given a rough surface by gluing sand to their base and sides. All tests were 
performed in a test box with length, width, and height of 920, 620, and $620 \mathrm{~mm}$, respectively (Fig. 6). The box was large enough to minimize the boundary condition effects and it was made of Plexiglas to provide better view of soil deformation. To reconstruct the sand at desired relative densities, i.e., $30 \%$ (loose) and $75 \%$ (dense), a new mobile sand pluviator system (Fig. 6), invented by Khari et al. (2014), was used. The use of this technique for achieving the desired relative density has been highlighted by many researchers (Madabhushi et al., 2006). The footings were placed at the center of the box and were driven (pushed) on the sand. Eid et al. (2009) mentioned that using this procedure will not lead to more than $4 \%$ bearing capacity overestimation. The testing tank was then placed over a frame made of 6-inch U-type steel profile $(1 \mathrm{inch}=2.54 \mathrm{~cm})$.

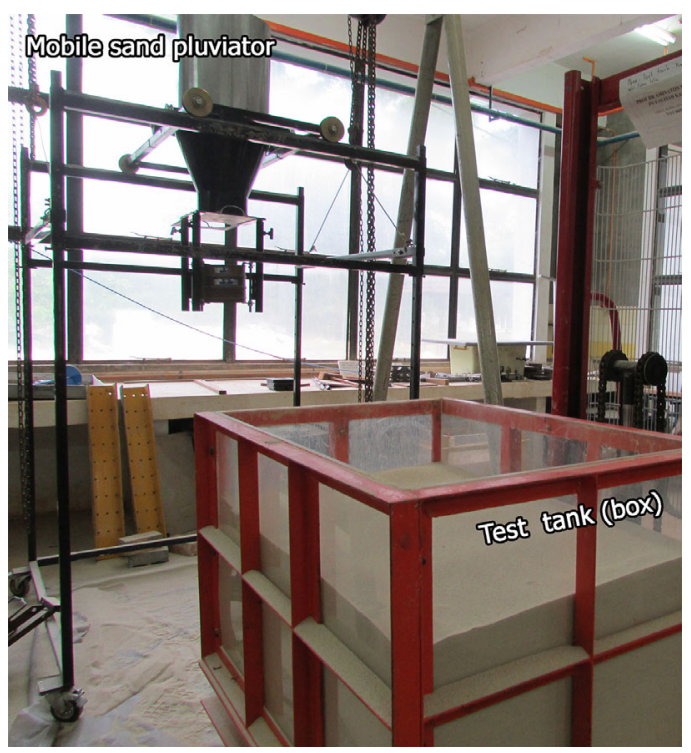

Fig. 6 Mobile sand pluviator and test tank

The load was applied slowly to the model footings by means of a pneumatic loading shaft in a continuous operation. The load was measured with a 20 -kN load cell with an accuracy of $\pm 0.01 \%$ resting between the footing and the load frame. The footing settlement was measured based on the readings of two linear variable displacement transducers (LVDT) installed on a reference beam (Fig. 7). The LVDT's accuracy was $\pm 0.01 \%$ of full range $(100 \mathrm{~mm})$.

The load was increased if the rate of settlement change was less than $0.003 \mathrm{~mm} / \mathrm{min}$ over 3 consecu- tive minutes. The use of this procedure was reported in several studies (Adams and Collin, 1997; Briaud and Gibbens, 1999; Chen et al., 2007). However, footings were loaded in relatively loose and dense sands until the soil settlement reached almost $25 \mathrm{~mm}$.

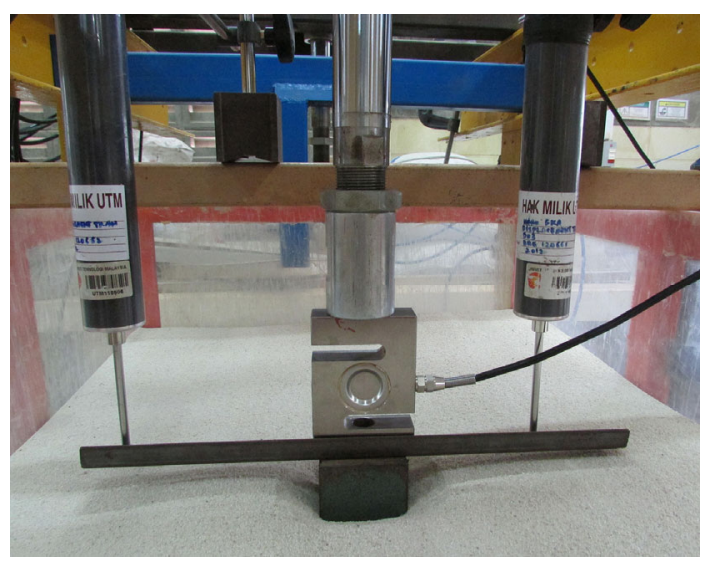

Fig. 7 Laboratory footing load test

\section{Results and discussion}

The superimposed load-displacement curves of footing load tests in loose sand are shown in Fig. 8. Overall, the results are not surprising. That is to say, for longer wall length, higher bearing capacity is expected. Fig. 8 suggests that the load carrying capacity of an IBS footing with shorter walls is $560 \mathrm{~N}$ while as expected, for an IBS footing with longer walls, the bearing capacity was found to be almost $830 \mathrm{~N}$.

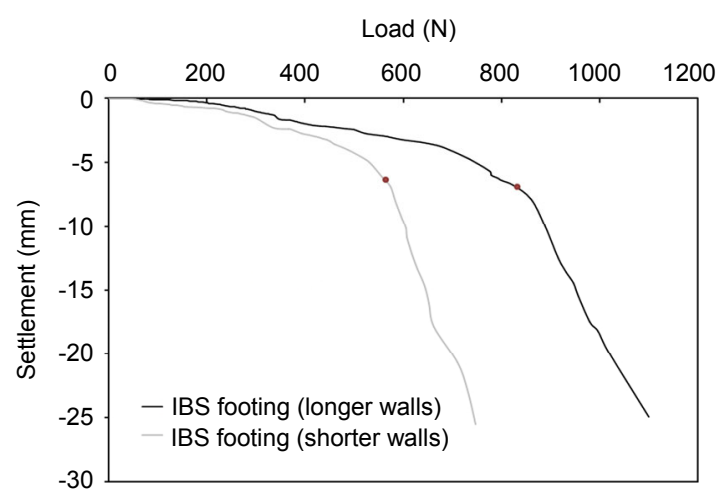

Fig. 8 Load-displacement curve of thin-walled footings in loose sand 
It is interesting to note that results suggest that selecting a value beyond $10 \%$ of footing width leads to bearing capacity overestimation. In fact, Fig. 8 suggests that the soil failure is captured when the soil deformation reached almost $8 \% B$. Although the figure is self explanatory, it should be highlighted that for interpreting the failure load, the recently proposed L1-L2 method (Akbas and Kulhawy, 2009) was utilized. In this method, the initial point $(L 2)$ of the last part of load-displacement curves is referred to as the axial bearing capacity of the footing. As displayed in Fig. 8, the effect of thin-walls on the transition part of load-displacement curves is obvious. Although the initial parts of curves are different to some extent that may generally be attributed to some uncertainties in conducting the tests. For example, reconstructing the sand in exactly the same density using sand raining technique is almost impossible and it is always expected to have sand a bit denser or looser than what is intended. This effect is more pronounced in loose sand compared with dense sand as the rate of sand raining, when constructing the loose sand, is much more than that of dense sand. Therefore, it is more difficult to achieve exactly the same relative density when the loose sand has to be reconstructed several times.

Nevertheless, similarly, the load-displacement curves of thin-walled footings in dense sands are presented in Fig. 9. According to Fig. 9, the bearing capacity of an IBS footing with shorter walls $\left(L_{\mathrm{w}} / B=0.5\right)$ is $1990 \mathrm{~N}$. For an IBS footing with longer walls $\left(L_{\mathrm{w}} / B=1.12\right)$, the load carrying capacity was found to be $2985 \mathrm{~N}$.

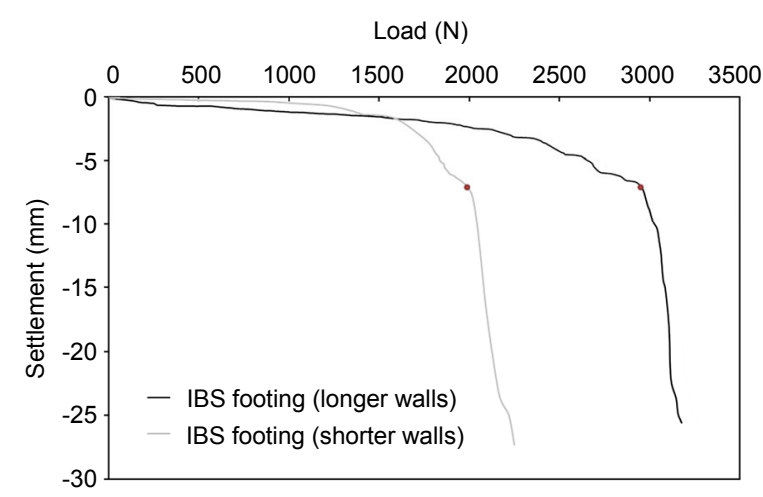

Fig. 9 Load-displacement curve of thin-walled footings in dense sand
Overall, Fig. 9 suggests that the general shear failure of sand is what is expected and it may be attributed to the dense state of the soil. Additionally, no specific bulging was observed for the IBS footing with either higher or shorter wall length (Fig. 10 as an example), which might be due to the incorporation of thin-walls. However, as stated in the study of Wakil (2013), it should be highlighted here that the bearing capacity failure is not necessarily grouped in three specific categories as proposed by Vesic (1973), i.e., general, local, and punching shear failure, mainly because these categories are suggested for unskirted footings.

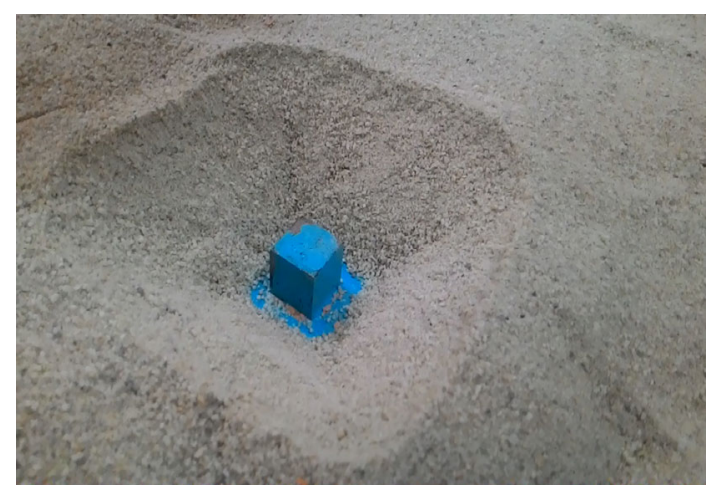

Fig. 10 IBS footing in dense sand after soil failure

Nevertheless, in thin-walled foundations, the soil located between walls is confined; hence, the footing and the confined soil inside the walls are acting as one integrated system. Consequently, as the length of walls increases, in a sense, the foundation embedded depth increases. Therefore, the bearing capacity of thin-walled foundations is enhanced as the wall length increases. However, in terms of negligible uncertainties in conducting the IBS footing load tests, a conclusion similar to loose sand can be drawn for dense sand as well, which in the interests of brevity is not repeated here. Overall, it was found that when $L_{\mathrm{w}} / B$ of the footings in both loose and dense sands is increased from 0.5 to 1.12 , the bearing capacity is increased almost 0.5 times.

This is in reasonable agreement with Wakil (2013)'s findings where he reported an almost 0.3 times increase in bearing capacity of thin-walled foundations in dense sands when $L_{\mathrm{w}} / B$ is increased from 0.5 to 1 . 
The results of different predictive models of bearing capacity described in the previous sections are also highlighted in this section. Fig. 11 shows the normalized predicted $Q_{\mathrm{u}}$ using PSO-based ANN, GA-based ANN as well as conventional ANN models versus the normalized measured bearing capacities of thin-walled spread foundations for the training dataset.

The correlation coefficient of PSO-based ANN model $(R=0.91)$ suggests that the proposed PSObased ANN model works better in predicting $Q_{\mathrm{u}}$ compared with GA-based ANN and conventional ANN. The $R$ values of GA-based ANN and conventional ANN are only 0.71 and 0.84 , respectively.

The prediction performance of the proposed models for the testing dataset is shown in Fig. 12. The correlation coefficient $R$ is equal to 0.98 in Fig. 12a, which also suggests the good reliability and relative superiority of the proposed PSO-based ANN model in predicting $Q_{\mathrm{u}}$. The correlation coefficients for GA-based ANN and conventional ANN of testing data are only 0.87 and 0.64 , respectively. This is in good agreement with Nazir et al. (2014) as well as Marto et al. (2014) who suggested the feasibility of the PSO-based ANN model in foundation engineering problems. Overall, the PSO-based ANN model performs best. Therefore, this study suggests the use of the PSO-based ANN model in predicting the bearing capacity of thin-walled foundations.

\section{Conclusions}

The close agreement between the measured and predicted (using the PSO-based ANN model) bearing capacities revealed the applicability of hybrid
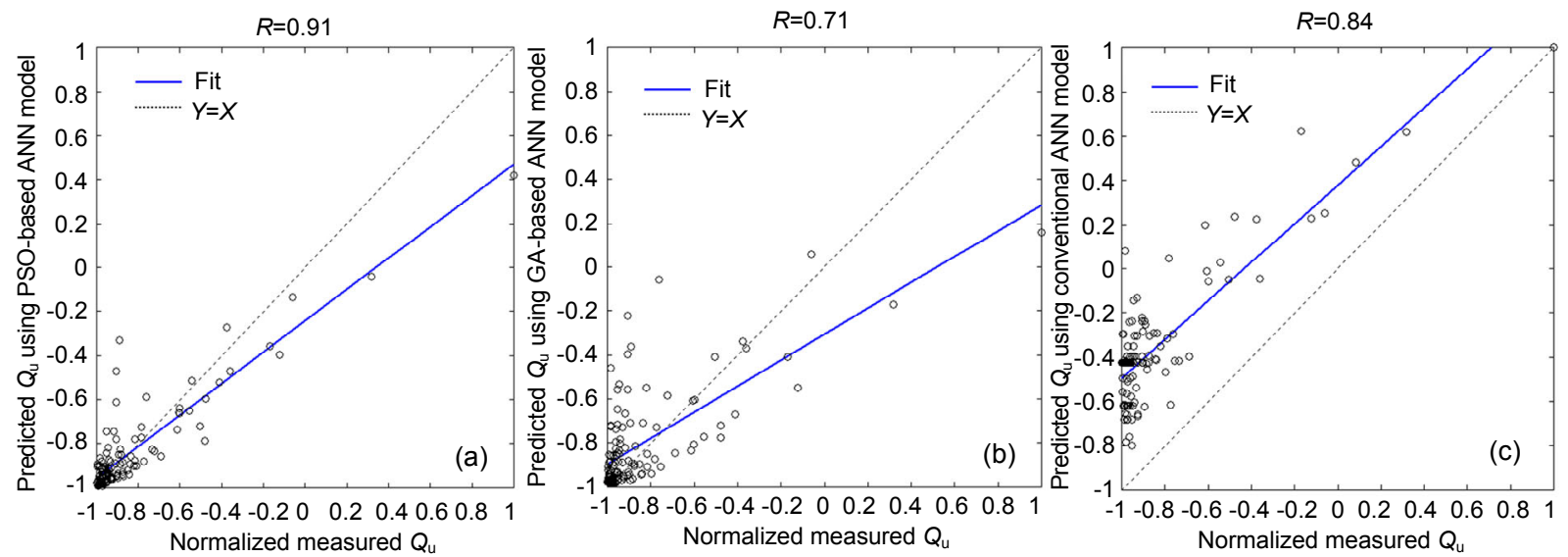

Fig. 11 Prediction performance of PSO-based ANN (a), GA-based ANN (b), and conventional ANN models (c) (training dataset)
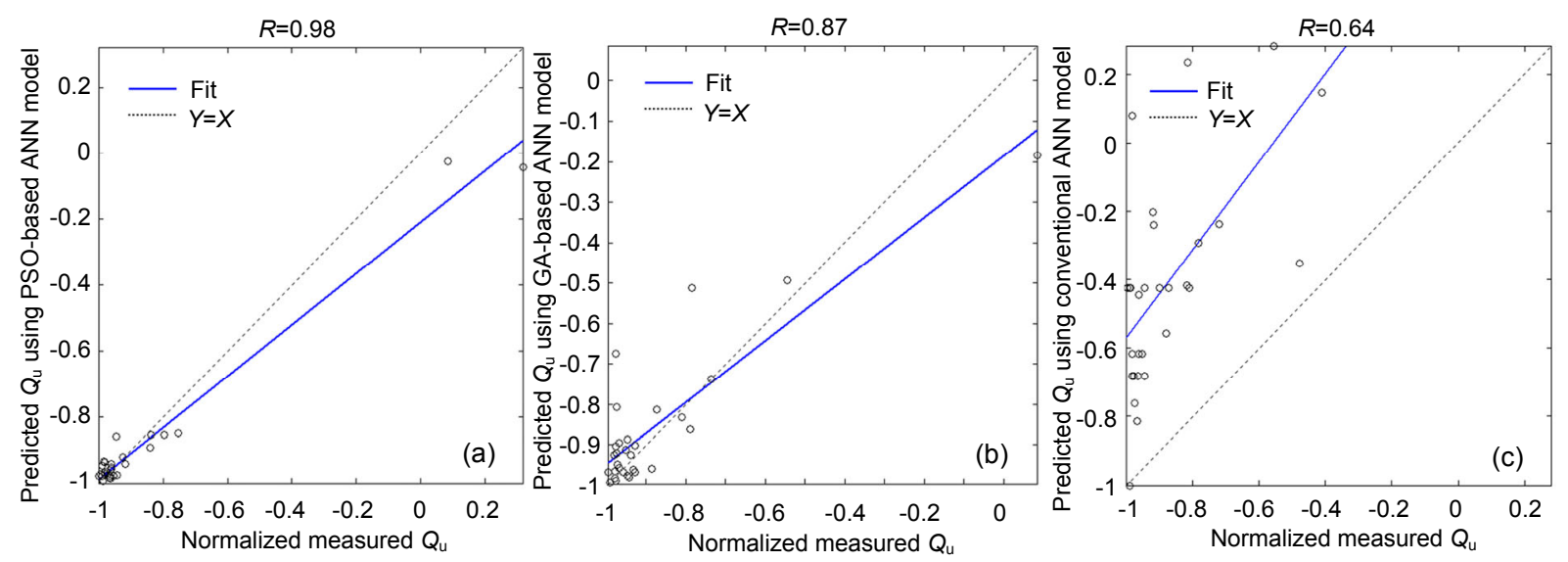

Fig. 12 Prediction performance of PSO-based ANN (a), GA-based ANN (b), and conventional ANN models (c) (testing dataset) 
ANNs, as a feasible, practical, and quick tool in predicting the bearing capacity of thin-walled spread foundations in cohesionless soils. The correlation coefficient $R$ and MSE equal to 0.98 and 0.005 , respectively, for the testing dataset indicated the superiority of the proposed predictive model, which was built with seven hidden nodes in one hidden layer. The correlation coefficients for GA-based ANN and conventional ANN were 0.80 and 0.65 , respectively. The dataset comprised 145 recorded cases of thinwalled footing load tests in sandy soils compiled from the literature as well as four conducted laboratory tests of this study. In particular, the laboratory tests confirmed the beneficial effect of wall length on the bearing capacity. It was found that a 0.5 times bearing capacity improvement is expected when $L_{\mathrm{w}} / B$ is increased from 0.5 to 1.12 .

\section{References}

Adams, M.T., Collin, J.G., 1997. Large model spread footing load tests on geosynthetic reinforced soil foundations. Journal of Geotechnical and Geoenvironmental Engineering, 123(1):66-72.

http://dx.doi.org/10.1061/(ASCE)1090-0241(1997)123:1 (66)

Akbas, S.O., Kulhawy, F.H., 2009. Axial compression of footings in cohesionless soils. I: Load-settlement behavior. Journal of Geotechnical and Geoenvironmental Engineering, 135(11):1562-1574.

http://dx.doi.org/10.1061/(ASCE)GT.1943-5606.0000135

Al-Aghbari, M.Y., Mohamedzein, Y.A., 2004. Model testing of strip footings with structural skirts. Proceedings of the ICE-Ground Improvement, 8(4):171-177. http://dx.doi.org/10.1680/grim.2004.8.4.171

Al-Aghbari, M.Y., Dutta, R.K., 2008. Performance of square footing with structural skirt resting on sand. Geomechanics and Geoengineering, 3(4):271-277. http://dx.doi.org/10.1080/17486020802509393

Alvarez Grima, M., Babuška, R., 1999. Fuzzy model for the prediction of unconfined compressive strength of rock samples. International Journal of Rock Mechanics and Mining Sciences, 36(3):339-349. http://dx.doi.org/10.1016/S0148-9062(99)00007-8

Benali, A., Nechnech, A., 2011. Prediction of the pile capacity in purely coherent soils using the approach of the artificial neural networks. International Seminar, Innovation and Valorization in Civil Engineering and Construction Materials, Rabat, Morocco, p.23-25.

Briaud, J.L., Gibbens, R., 1999. Behavior of five large spread footings in sand. Journal of Geotechnical and Geoenvironmental Engineering, 125(9):787-796. http://dx.doi.org/10.1061/(ASCE)1090-0241(1999)125:9 (787)
Chen, Q., Abu-Farsakh, M.Y., Sharma, R., et al., 2007. Laboratory investigation of behavior of foundations on geosynthetic-reinforced clayey soil. Transportation Research Record: Journal of the Transportation Research Board, 2004:28-38. http://dx.doi.org/10.3141/2004-04

Dreyfus, G., 2005. Neural Networks: Methodology and Application. Springer Berlin Heidelberg, Germany.

Eberhart, R.C., Shi, Y., 2001. Tracking and optimizing dynamic systems with particle swarms. Proceedings of the Congress on Evolutionary Computation, Seoul, Korea, p. $94-100$. http://dx.doi.org/10.1109/CEC.2001.934376

Eid, H.T., 2013. Bearing capacity and settlement of skirted shallow foundations on sand. International Journal of Geomechanics, 13(5):645-652. http://dx.doi.org/10.1061/(ASCE)GM.1943-5622.0000237

Eid, H.T., Alansari, O.A., Odeh, A.M., et al., 2009. Comparative study on the behavior of square foundations resting on confined sand. Canadian Geotechnical Journal, 46(4):438-453. http://dx.doi.org/10.1139/T08-134

Fausett, L.V., 1994. Fundamentals of Neural Networks: Architecture, Algorithms and Applications. Prentice-Hall, Englewood Cliffs, NJ, USA.

Garrett, J.H., 1994. Where and why artificial neural networks are applicable in civil engineering. Journal of Computing in Civil Engineering, 8(2):129-130. http://dx.doi.org/10.1061/(ASCE)0887-3801(1994)8:2(129)

Gibbens, R.M., Briaud, J.L., 1995. Load Tests on Five Large Spread Footings on Sand and Evaluation of Prediction Methods. MS Thesis, Texas A\&M University, College Station, TX, USA.

Goh, A.T., 1996. Pile driving records reanalyzed using neural networks. Journal of Geotechnical Engineering, 122(6): 492-495. http://dx.doi.org/10.1061/(ASCE)0733-9410(1996)122:6 (492)

Habib, P.A., 1974. Scale effect for shallow footings on dense sand. Journal of Geotechnical and Geoenvironmental Engineering, 100(GT1):95-99.

Hagan, M.T., Demuth, H.B., Beale, M.H., et al., 1996. Neural Network Design. PWS Publishing Company, Boston, USA.

Holland, J., 1975. Adaptation in Natural and Artificial Systems. The University of Michigan Press, Ann Arbor, USA.

Hornik, K., Stinchcombe, M., White, H., 1989. Multilayer feedforward networks are universal approximators. $\mathrm{Neu}$ ral Networks, 2(5):359-366. http://dx.doi.org/10.1016/0893-6080(89)90020-8

Jadav, K., Panchal, M., 2012. Optimizing weights of artificial neural networks using genetic algorithms. International Journal of Advanced Research in Computer Science and Electronics Engineering, 1:47-51.

Jahed Armaghani, D., Tonnizam Mohamad, E., Momeni, E., 
et al., 2014. An adaptive neuro-fuzzy inference system for predicting unconfined compressive strength and Young's modulus: a study on Main Range Granite. Bulletin of Engineering Geology and the Environment, 74(4):1301-1319. http://dx.doi.org/10.1007/s10064-014-0687-4

Kalinli, A., Acar, M.C., Gunduz, Z., 2011. New approaches to determine the ultimate bearing capacity of shallow foundations based on artificial neural networks and ant colony optimization. Engineering Geology, 117(1-2):2938.

http://dx.doi.org/10.1016/j.enggeo.2010.10.002

Kennedy, J., Eberhart, R., 1995. Particle swarm optimization. IEEE International Conference on Neural Networks, Perth, Australia, p.1942-1948.

Khari, M., Kassim, K.A., Adnan, A., 2014. Sand samples' preparation using mobile pluviator. Arabian Journal for Science and Engineering, 39(10):6825-6834. http://dx.doi.org/10.1007/s13369-014-1247-8

Kiefa, M.A., 1998. General regression neural networks for driven piles in cohesionless soils. Journal of Geotechnical and Geoenvironmental Engineering, 124(12):11771185.

http://dx.doi.org/10.1061/(ASCE)1090-0241(1998)124:1 2(1177)

Lee, Y., Oh, S.H., Kim, M.W., 1991. The effect of initial weights on premature saturation in back-propagation learning. International Joint Conference on Neural Networks, Seattle, USA, 1:765-770. http://dx.doi.org/10.1109/IJCNN.1991.155275

Liu, T.X., Zhang, S.W., Wu, Q.Y., et al., 2012. Research of agricultural land classification and evaluation based on genetic algorithm optimized neural network model. In: Wu, Y.W. (Ed.), Software Engineering and Knowledge Engineering: Theory and Practice. Springer Berlin Heidelberg, Germany, p.465-471.

http://dx.doi.org/10.1007/978-3-642-25349-2 62

Lok, T.M.H., Che, W.F., 2004. Axial capacity prediction for driven piles using ANN: model comparison. Geotechnical Engineering for Transportation Projects, Los Angeles, USA, p.697-704. http://dx.doi.org/10.1061/40744(154)56

Madabhushi, S.P.G., Houghton, N.E., Haigh, S.K., 2006. A new automatic sand pourer for model preparation at University of Cambridge. Proceedings of the 6th International Conference on Physical Modelling in Geotechnics, London, UK, p.217-222.

Majdi, A., Beiki, M., 2010. Evolving neural network using a genetic algorithm for predicting the deformation modulus of rock masses. International Journal of Rock Mechanics and Mining Sciences, 47(2):246-253. http://dx.doi.org/10.1016/j.ijrmms.2009.09.011

Marto, A., Hajihasaani, M., Momeni, E., 2014. Prediction of bearing capacity of shallow foundation through hybrid artificial neural networks. Applied Mechanics and Materials, 567:681-686.
Mendes, R., Cortes, P., Rocha, M., et al., 2002. Particle swarms for feed forward neural net training. Proceedings of the IEEE International Conference on Neural Networks, Honolulu, HI, USA, p.1895-1899.

Meulenkamp, F., Alvarez Grima, M., 1999. Application of neural networks for the prediction of the unconfined compressive strength (UCS) from Equotip hardness. International Journal of Rock Mechanics and Mining Sciences, 36(1):29-39. http://dx.doi.org/10.1016/S0148-9062(98)00173-9

Meyerhof, G.G., 1963. Some recent research on the bearing capacity of foundations. Canadian Geotechnical Journal, 1(1):16-26. http://dx.doi.org/10.1139/t63-003

Momeni, E., Maizir, H., Gofar, N., et al., 2013. Comparative study on prediction of axial bearing capacity of driven piles in granular materials. Jurnal Teknologi, 61(3):1520. http://dx.doi.org/10.11113/jt.v61.1777

Momeni, E., Nazir, R., Jahed Armaghani, D., et al., 2014. Prediction of pile bearing capacity using a hybrid genetic algorithm-based ANN. Measurement, 57:122-131. http://dx.doi.org/10.1016/j.measurement.2014.08.007

Momeni, E., Nazir, R., Jahed Armaghani, D., et al., 2015a. Application of artificial neural network for predicting shaft and tip resistance of concrete piles. Earth Sciences Research Journal, 19(1):85-93. http://dx.doi.org/10.15446/esrj.v19n1.38712

Momeni, E., Nazir, R., Jahed Armaghani, D., et al., 2015 b. Bearing capacity of precast thin-walled foundation in sand. Geotechnical Engineering, 168(6):539-550.

Momeni, E., Jahed Armaghani, D., Hajihassani, M., et al., 2015c. Prediction of uniaxial compressive strength of rock samples using hybrid particle swarm optimizationbased artificial neural networks. Measurement, 60:50-63. http://dx.doi.org/10.1016/j.measurement.2014.09.075

Nazir, R., Momeni, E., Marsono, K., et al., 2013. Precast spread foundation in industrialized building system. Proceedings of the 3rd International Conference on Geotechnique, Construction Materials and Environment, Nagoya, Japan, p.13-15.

Nazir, R., Momeni, E., Hajihassani, M., 2014. Prediction of spread foundation's settlement in cohesionless soils using a hybrid particle swarm optimization-based ANN approach. International Conference on Advances in Civil, Structural and Mechanical Engineering, London, UK, p.20-24.

Ornek, M., Laman, M., Demir, A., et al., 2012. Prediction of bearing capacity of circular footings on soft clay stabilized with granular soil. Soils and Foundations, 52(1):69-80. http://dx.doi.org/10.1016/j.sandf.2012.01.002

Padmini, D., Ilamparuthi, K., Sudheer, K., 2008. Ultimate bearing capacity prediction of shallow foundations on cohesionless soils using neurofuzzy models. Computers and Geotechnics, 35(1):33-46. 
http://dx.doi.org/10.1016/j.compgeo.2007.03.001

Pal, M., Deswal, S., 2008. Modeling pile capacity using support vector machines and generalized regression neural network. Journal of Geotechnical and Geoenvironmental Engineering, 134(7):1021-1024.

http://dx.doi.org/10.1061/(ASCE)1090-0241(2008)134:7 (1021)

Rabbani, E., Sharif, F., Koolivand Salooki, M., et al., 2012. Application of neural network technique for prediction of uniaxial compressive strength using reservoir formation properties. Journal of Rock Mechanics and Mining Sciences, 56:100-111. http://dx.doi.org/10.1016/j.ijrmms.2012.07.033

Rashidian, V., Hassanlourad, M., 2013. Predicting the shear behavior of cemented and uncemented carbonate sands using a genetic algorithm-based artificial neural network. Geotechnical and Geological Engineering, 31(4):12311248.

http://dx.doi.org/10.1007/s10706-013-9646-2

Shahin, M.A., 2015. A review of artificial intelligence applications in shallow foundations. International Journal of Geotechnical Engineering, 9(1):49-60. http://dx.doi.org/10.1179/1939787914Y.0000000058

Shahin, M.A., Jaksa, M.B., Maier, H.R., 2001. Artificial neural network application in geotechnical engineering. Australian Geomechanics, 36(1):49-62.

Shi, Y., Eberhart, R., 1998. Parameter selection in particle swarm optimization. Evolutionary Programming VII: 7th International Conference, San Diego, California, USA, p.591-600. http://dx.doi.org/10.1007/BFb0040810

Shi, Y., Eberhart, R., 1999. Empirical study of particle swarm optimization. Proceedings of the IEEE Congress on Evolutionary Computation, New York, p.1945-1950.

Singh, V.K., Singh, D., Singh, T.N., 2001. Prediction of strength properties of some schistose rocks from petrographic properties using artificial neural networks. International Journal of Rock Mechanics and Mining Sciences, 38(2):269-284. http://dx.doi.org/10.1016/S1365-1609(00)00078-2

Soleimanbeigi, A., Hataf, N., 2006. Prediction of settlement of shallow foundations on reinforced soils using neural networks. Geosynthetics International, 13(4):161-170. http://dx.doi.org/10.1680/gein.2006.13.4.161

Taylor, R.N., 1995. Geotechnical Centrifuge Technology, 1st Edition. Chapman \& Hall, London, UK.

Terzaghi, K., 1943. Theoretical Soil Mechanics. John Wiley and Sons, Inc., New York. http://dx.doi.org/10.1002/9780470172766

Tonnizam Mohamad, E., Jahed Armaghani, D., Momeni, E., 2014. Prediction on unconfined compressive strength of soft rocks: a PSO-based ANN approach. Bulletin of Engineering Geology and the Environment, 74(3):745-757. http://dx.doi.org/10.1007/s10064-014-0638-0
Tripathy, S., 2013. Load Carrying Capacity of Skirted Foundation on Sand. MS Thesis, National Institute of Technology, Rourkela, India.

Vesic, A.S., 1973. Analysis of ultimate loads of shallow foundations. Journal of the Soil Mechanics and Foundations Division, 99(1):45-73.

Villalobos, F., 2007. Bearing capacity of skirted foundations in sand. VI Congreso Chileno de Geotecnia, Valparaiso, Chile.

Wakil, A.Z.E.L., 2013. Bearing capacity of skirt circular footing on sand. Alexandria Engineering Journal, 52(3):359364.

http://dx.doi.org/10.1016/j.aej.2013.01.007

Zhao, J.B., Tu, J.W., Shi, Y.Q., 2010. An ANN model for predicting level ultimate bearing capacity of PHC pipe pile. Earth and Space, p.3168-3176. http://dx.doi.org/10.1061/41096(366)302

Zorlu, K., Gokceoglu, C., Ocakoglu, F., et al., 2008. Prediction of uniaxial compressive strength of sandstones using petrography-based models. Engineering Geology, 96(34):141-158.

http://dx.doi.org/10.1016/j.enggeo.2007.10.009

\section{中文概要}

题 目: 基于人工智能的薄壁浅地基的承重能力研究

目 的: 薄壁扩展式地基已被广泛应用于土壤强度相对 较低的沿海工程。目前, 已有很多学者对其进 行了人工神经网络的适用性研究, 希望用此对 地基的承重能力进行预测。但是这些研究多数 是基于传统的人工神经网络, 学习速度慢且受 困于局部极小值。本文拟提出一种改进的基于 人工神经网络的预测薄壁浅地基承重能力的 模型。

方 法: 1. 整合 145 组关于地基承重测试的文献数据和 实验数据 (包括承重能力、摩擦角、沙的单位 重量、基脚宽度和长宽比等); 除了承重能力, 其他参数都是模型输入; 2 . 研究各参数对地基 承重能力的影响, 确定最优的人工神经网络模 型参数, 并对不同的人工神经网络模型进行 比较。

结 论: 1 . 当基脚长宽比从 0.5 变为 1.12 时, 地基的承重 能力增加了大约一半; 2. 基于粒子群优化算法 的人工神经网络模型表现最好; 在测试数据 中, 承重能力的预测值和测量值之间高达 0.98 的相关系数也表明, 在无粘性土中, 基于人工 神经网络的预测模型适用于薄壁浅地基的承重 能力预测。

关键词: 薄壁地基; 沙; 承重能力; 人工神经网络; 粒 子群优化 